\title{
The use of semi-automatic technique of finite elements mesh generation for solutions of some railway transport problems
}

\author{
A. Sladkowski*, K. Bizoń** \\ *Silesian University of Technology, Krasińskiego 8, 40-019 Katowice, Poland, E-mail: aleksander.sladkowski@polsl.pl \\ **Silesian University of Technology, Krasińskiego 8, 40-019 Katowice, Poland, E-mail: krzysztof.bizon@polsl.pl \\ cross $^{\text {ref }}$ http://dx.doi.org/10.5755/j01.mech.23.2.18109
}

\section{Introduction}

The finite element method is used for a long time to solve the various problems of rail transport. For example, it use to study the dynamics of the interaction between the wheel, which has a flat place, and the rail with the railroad bed [1]. To solve the problem, which requires a significant amount of time calculations, the authors greatly simplify the geometry of the objects under consideration. Simultaneously performed the substantial concentration of FE meshes of wheel and rail in the contact zone.

In solving of the global problems related to structural dynamics, the authors usually do not attach much importance to local contact problems. For example, in article [3] the author analyzes the building vibration induced by high-speed trains moving on bridges. In this case, the author uses specific elements that should simulate the interaction of wheel and rail. This approach allows to linearize the problem and to use the FE meshes containing about one million nodes.

The authors of the article [2] proceed similarly, regarding the structural dynamics of the freight wagon. In this case, they don't focus on the dynamics of interaction, for example, individual parts and assembling of wagon suspension or coupling devices. This allows to solve problems using sufficiently large FE meshes (569003 nodes).

It should be noted that the authors usually automatically generate FE meshes. There may be certain authors intervention in this process associated with the choice of the type of elements, number of nodes, etc. However, the question of meshes matching in the contact area often not considered. For example, the authors of the paper [6] to create of a FE meshes of bogie frame used elements of different types. However, issues related to the coordination of this mesh with other parts not considered.

In a number of problems related to the rail transport the contact phenomena have a special importance. These problems include issues of the interaction of the wheels and rails, the interaction of the individual parts of switches, the interaction of the catenary contact wire and pantograph bow, etc. In this case, the generation of FE mesh has a special significance. For example, in article [13] the authors regulate the density of FE meshes depending on the contact area under consideration. Such meshes must be regular. Special contact elements may be used here, for example in this paper used contact element CONTA174.

\section{Rail fastenings of SB-3 type}

As an example, the use of finite element method to solve problems of rail transport, consider the use of this method to the elastic rail fastenings. Currently there are a lot of designs of railway tracks, which are used for underground or tram. Nevertheless, among them the leading place belongs to traditional designs, which are based on the use of rails - sleeper solutions. At the same time very important are the methods of fixing rails to the sleepers. There are many technical solutions that use elastic elements (springs) for such fastening. The advantage of such fastening is that it generally don't require additional maintenance or adjustment control.

Already for a long time in Poland for fixing of the rails of the main and industrial rail transport used rail fasteners of SB-3 type. There are a number of modifications of these rail fastenings. The advantage of such structures is fairly simple installation, no need for often periodic monitoring or adjustment. These advantages have resulted in their wide use for the main railways. Currently, there is the implementation of this technical solution also in the industrial transport, tramways and subways. It should be noted that such a structure can be opened and can be concreted or backfilled, as shown in Fig. 1 [12].

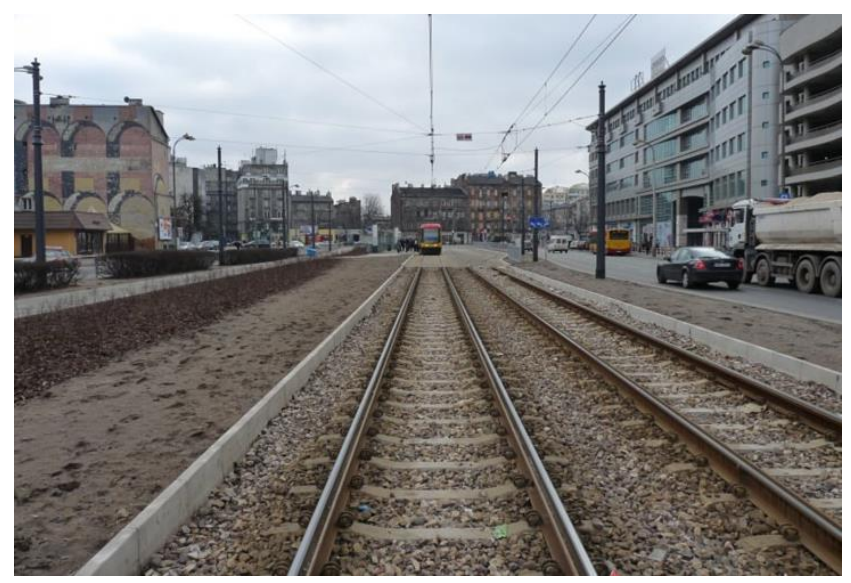

Fig. 1 One of the modifications of the rail fastening of SB3 type used for tram tracks in Warsaw

Rail fastening of SB type are a spring anchoring. Pressing screws used in the previously applied solutions (rigid fastening of $\mathrm{K}$ type, spring fastening of Skl type) have been replaced by the spring elements (so-called spring clips) and they are the main mounting element responsible for the pressing of the rail to the sleeper. Rail fastenings of SB type are generally used with the concrete sleepers. Rail fastenings of SB type are one of the most modern types of fastenings which can be used both for rail tracks, trams or metro. They are characterized by fast as- 
sembly and disassembly, amortization of vibrations coming from the rolling stock and a very good electrical isolation limiting to a minimum the traction stray currents, high durability, the possibility of use on high-speed lines (above $120 \mathrm{~km} / \mathrm{h}$ ), a small amount of components, the reduction of noise and vibration (especially important for passenger trains), the possibility of mounting by mechanical means or by hand. The example of SB-3 fastening is shown in Fig. 2. In the sleeper (1) are concreted the anchors (2). In the anchors are embedded spring clips (3), which by means electrical insulating inserts (4) press the rail (5) to the rail pad (6) resting directly on the sleeper.
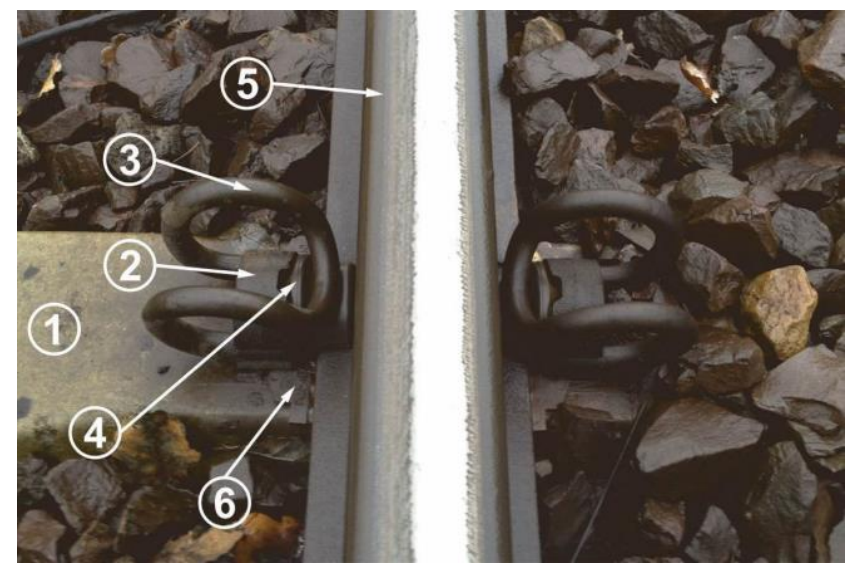

Fig. 2 Rail fastening of SB-3 type

The system for anchoring of the rails to the sleepers must satisfy the requirements of seven Polish and European standards [9] supplemented by eight other standards [8]. The standards of 13481 series specify requirements to be fulfilled by fastening systems for wooden, concrete and steel sleepers, for the pavement without ballast and for crossovers. Standardized test methods and criteria for uniform assessment of any fastening systems are described by the series of standards no. 13146. They concern the following tests [7]: the rails;

- determination of the longitudinal resistance of

- determination of the twisting resistance;

- determination of dynamic loads damping;

- study the effect of repetitive loads;

- determination of the resistance; conditions;

- study the impact of extreme environmental

- determination of the clamping force;

- operational research.

Most of these studies are performed on a specially-prepared laboratory equipment.

The authors have attempted to preparation of a computational model of SB-3 rail fastening using the finite element method (FEM), which would allow a preliminary estimate of the parameters on the base of the designated laboratory tests conducted using actual fastening rails to the sleepers. Studies using model of mounting, model based on the finite element method, to conduct numerical calculations at the design stage of new developments of fixings. For example, when designing a new shape of elastic clips, under rail pads, using of new materials, etc.

\section{Geometric model of the SB-3 type fastening and au- tomatic mesh generation}

On the basis of the technical documentation was made geometrical models of the following components of SB-3 fastening:

- spring clip SB7;

- head of the anchor SB3/P;

- pressure pad WKW 60;

- rail S60 (fragment);

- rail pad PWE6094;

- sleeper PS94 (fragment).

Geometrical models of the fastening elements are made with using of Autodesk Inventor Professional. The same program was used to complete the assembling of all mounting elements (Fig. 3). Geometric model of the fastening preparing in Autodesk Inventor Professional has been used only partially during discrete modelling of this assembling. Discrete model was made using MSC.MARC. Direct use of geometric, spatial models of fastening elements to generate their discrete models was not possible due to the lack of full control over the size, shape and number of finite elements for discretization of given geometric model. Imposing of spatial mesh for solid geometrical model was only possible with the help of automated modules, which has the program MSC.MARC.

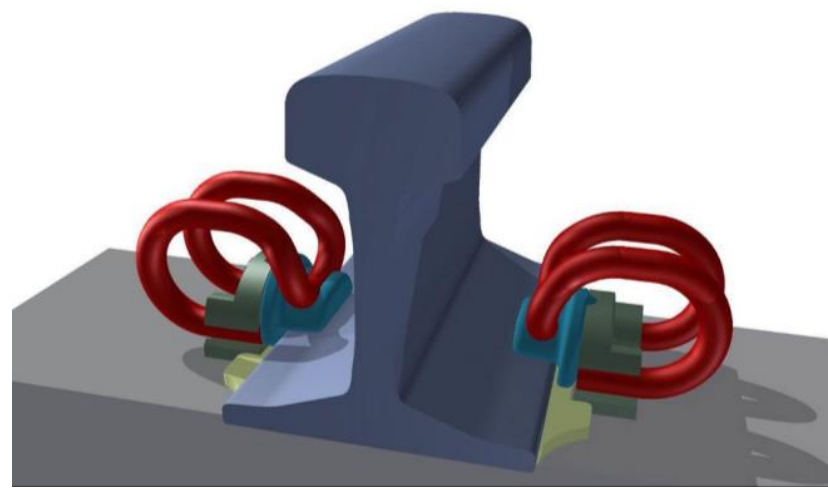

Fig. 3 Geometrical model of elastic fastening of SB-3 type
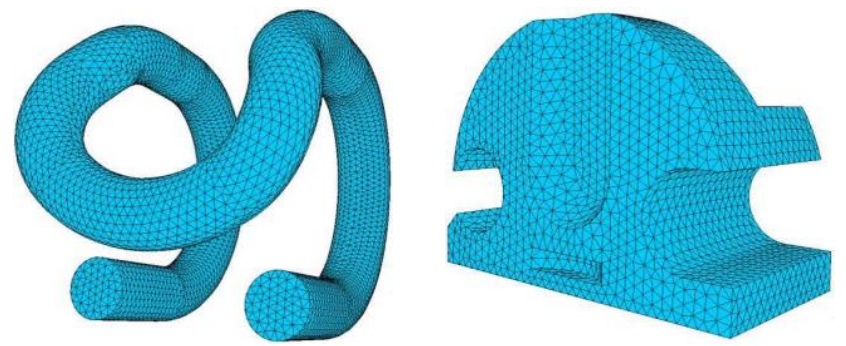

Fig. 4 Discrete models of the spring clip (left) and the anchor head (right) created with the use of automatic FE mesh generation

The choice of MSC.MARC program was due to several factors:

- for solutions of contact problems do not require introduction of special contact elements, as described above;

- the program allows the use of parallelization process solutions using the FE meshes partitioning into separate clusters;

- the program uses a variety of algorithms for solving various multiphysics problems, including coupled 
problems;

- program is partially open, allowing the creation and further linking of the individual modules written with using Fortran or $\mathrm{C}++$.

Fig. 4 shows examples of FE meshes obtained using an automated mesh generator of the program MSC.MARC.

\section{Some problems of FE mesh generation for discrete model of SB-3 type fastening and solutions}

Due to the fact that the model of SB-3 fastening will act as the test model, the material properties of fastening parts taken as the constant. The values of properties of materials (steel, cast iron, glass fiber reinforced polyamide, polyurethane, concrete) is derived from publicly available sources of literature $[4,5]$ and the Internet, for example, sites of producers of the spring clips. It was defined Young's modulus, Poisson's ratios as well as the coefficients of friction between the mating (remaining in the contact) parts of the fastening. The assumption of constant values for material properties seems to be particularly high in the case of simplification of the rail pad. Currently, authors of the project carry out additional research aiming at elaborating of nonlinear characteristics of the materials of selected fastening parts. This is particularly important in the case of the rail pad made from polyurethane and an insulating insert made from glass fiber reinforced polyamide.
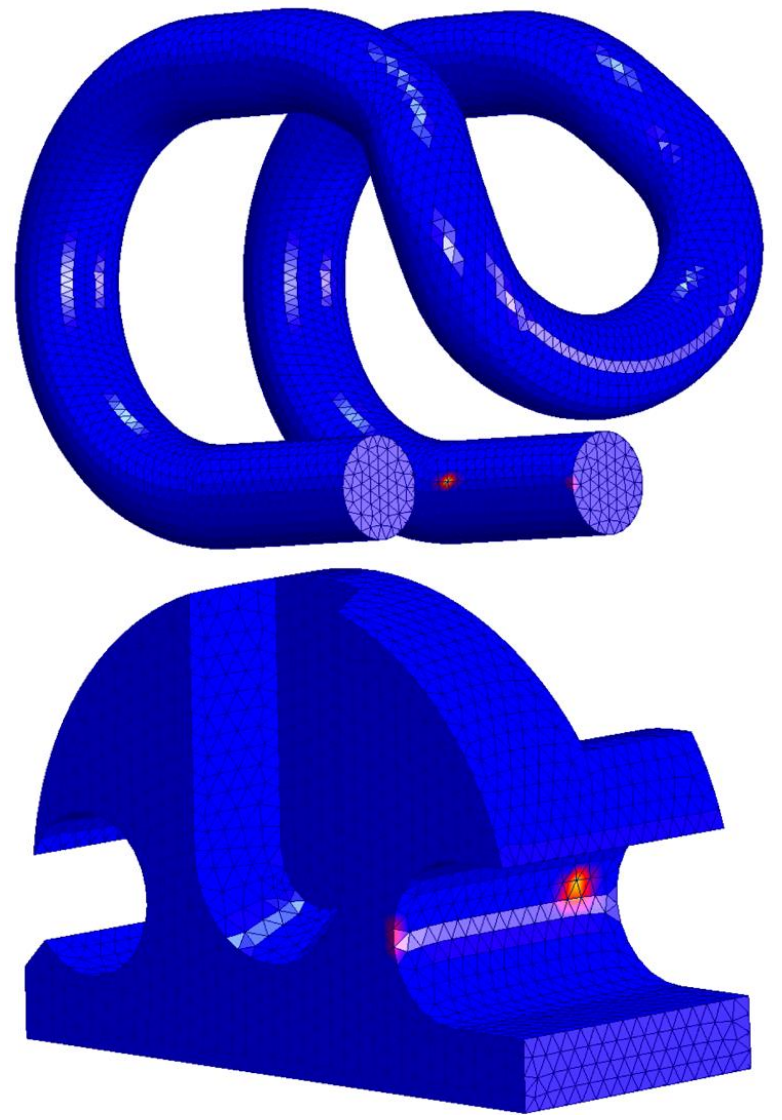

Fig. 5 Distribution of contact stresses on the surface of the spring clip (first) and the anchor head (second) for automatic FE mesh generation

Unfortunately, the authors faced with the fact that the obtained solution for the problem of contact interaction of the above parts is inadequate. Fig. 5 shows the distribution of contact stresses on the surface of the spring clip. The above stress distribution indicates that there is contact between surfaces in only two nodes on each side.

Increasing the number of nodes and the corresponding reduction in the maximum size of the finite elements do not lead to an improvement in the solution, but only significantly increase the time of calculation. Fig. 6 shows the dependence of operation time on the maximal size of the elements.

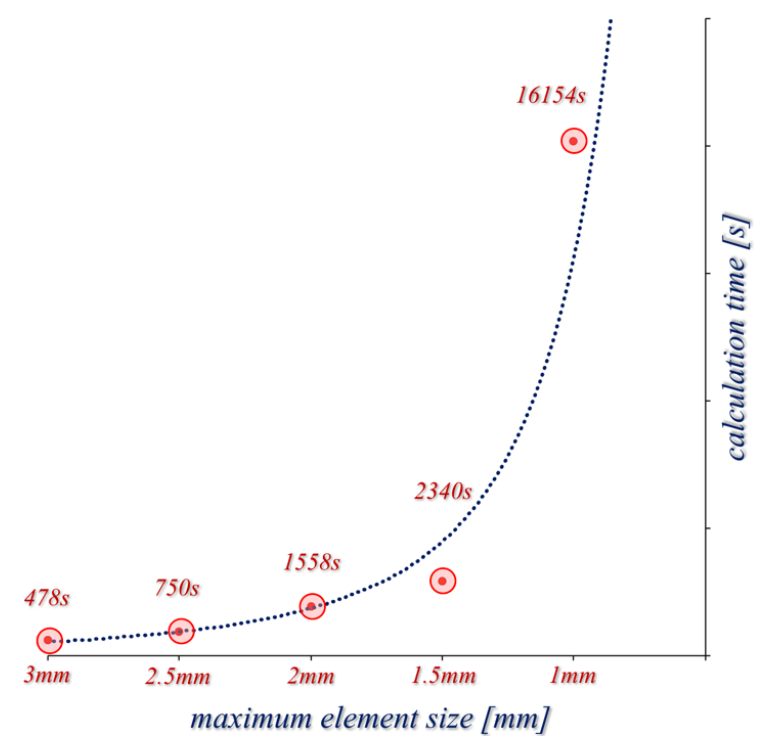

Fig. 6 Dependence of operation time on the maximal size of the elements for the problem of contact interaction between elastic clip and anchor head

Calculations were carried out on the computer with a processor Intel Core 2 Quad Q6600 2,4 GHz and 8GB RAM. Thus, the reduction in the maximum size of a finite elements three times causes an increase in the calculation time is almost 34 times. Obviously, this approach is a dead end. Especially because for contact problems, which are essentially non-linear, and therefore their solution is an iterative, it requires a lot of computer resources. It is normally necessary try to create FE meshes with a minimum number of nodes. In such case what is the cause of inadequate reception results?

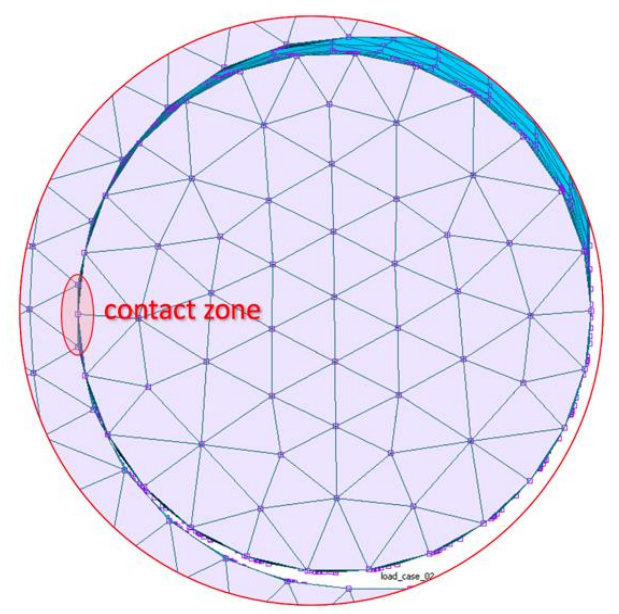

Fig. $7 \mathrm{FE}$ meshes of interacted parts of rail fastening, which created with the use of automatic FE mesh generation 
The answer can be found in the articles [10, 11]. The main reason for the inadequate results of the solution of contact problems using the FEM is lack of coordination of FE meshes. This can be demonstrated due the analysis of the contact of considered parts in Fig. 7.

We see here that the FE meshes are noncoordinated in the contact zone. Unfortunately, the program MSC.MARC has no possibility of FE meshes coordination of interacting parts. The authors don't know whether there is such a possibility in the case of other programs. As a consequence there was a need to develop a technique of FE meshes coordination with the use of semiautomatic generation.

The coordinated discrete model of SB-3 rail fastening was made using the program MSC.MARC. There was used the opportunity of the cooperation of MSC.MARC program with batch files of .procedure type. Batch files of .procedure type are text files in which each line of text is a command understandable for MSC.MARC program. The program reads the .procedure file and executes one after other commands which written here. This way of working with the program causes that it is easy to make changes to the model. The ability of easily and quickly modification of the text file, for example, allows you to control the size and shape of the finite elements for forming discrete models of different parts of the fastening. The possibility of such control gives opportunity to adjust the FE mesh of pairs of contacting parts in such a way that the nodes of the elements in contact will occupy the same location in space, in other words have been agreed. Such alignment of nodes is necessary for the correct analysis of contact problems for discrete model of the mating fastening parts.

The limited use of the elements of a geometric model to build the discrete model involves using only some of its curves and points. An example of such a method of building the discrete model can be to build a model of discrete elastic clip. In this case, the geometrical model was restricted to only a few curves defining a circular cross section and clip leading curve, after which the "dragged" flat FE mesh to generate a spatial mesh of FE model forming discrete elastic clip.

The number of FE nodes for the four curves bound the circular transverse section of the elastic clamp, the number of FE nodes on the four auxiliary sections (somewhat radii of clamp circular cross-section) could be defined in any way, both the number and the position along the curves. The leading curve of the elastic clamp was divided into several curves. The number of solid finite elements generated along the leading curve based on the flat FE mesh for cross-section of elastic clamp, could also be defined in any way. Following the procedure described above was obtained the discrete model of elastic clamps made from the finite elements, whose number, size and shape are controlled.

This approach was used to generate the FE meshes of the other parts of the rail fastening. The main objective was to create a FE meshes with the minimum number of nodes that would nevertheless adequately describes the stress state of the system. At the same time the contact nodes of interacting parts had to be coordinated with each other. It was possible to implement using a semiautomatic mesh generation, similarly to what has been described above. Obviously, minor geometry simplifications of some

parts were made. But this does not significantly affect on the distribution of stresses and strains. As an example, the following Fig. 8 shows the FE models of parts with most complex geometries.

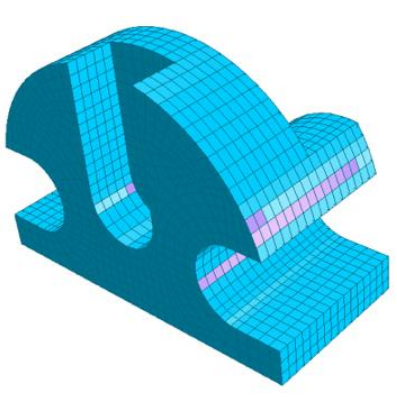

a

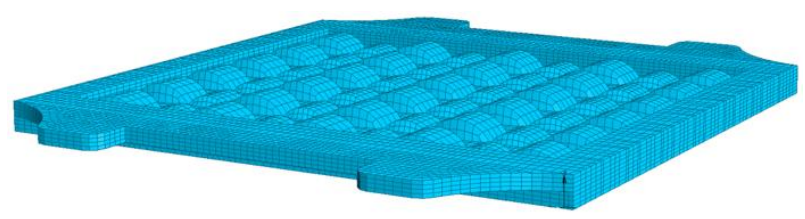

c

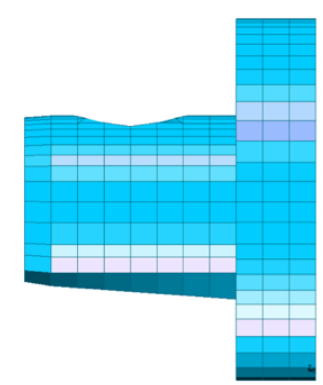

b
Fig. 8 FE models of parts with most complex geometries: a - the head of the anchor, which is installed in the sleeper; $b$ - insulating insert between the clip and the rail foot; c - elastic pad

Rail fastening of SB-3 type have a lot of contact zones between the individual parts. If we consider the connection between the elastic clip and the anchor head, the nodes coordination must be carried out in two coordinates (longitudinal and circumferential). Fig. 9 shows that such coordination has been successfully implemented.

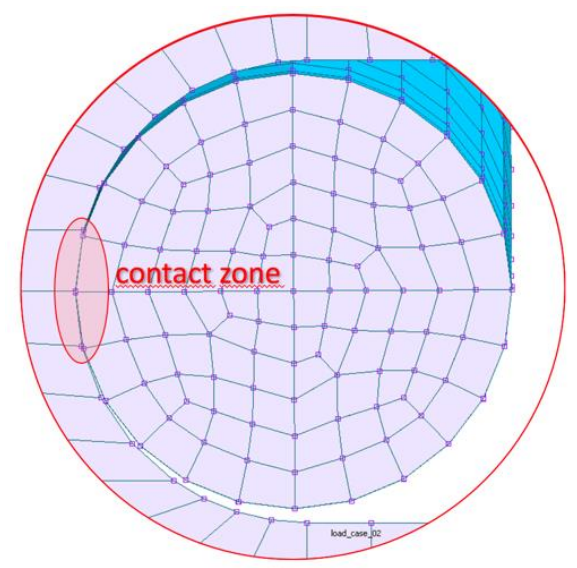

Fig. 9 FE meshes of interacted parts of rail fastening, which created with the use of coordination technique and semi-automatic FE mesh generation

Fig. 10 shows the distribution of contact stresses on the surfaces of the interacting elements of the elastic clips and the anchor head. As seen from the figures, the distribution is quite adequate, there are contact areas with a uniform stress distribution.

Fig. 11 shows the FE model of the entire rail fastening assembly of SB-3 type. The advantage of this model was that as a result of the semi-automatic generation of FE meshes of individual parts could create the model of the assembly, which contains the minimum number of nodes 
and the meshes of parts was agreed in the contact areas. These advantages allow to implement solution of the problem on PCs without the need for use of supercomputers and cluster solutions. At present first results were obtained which are quite adequate.

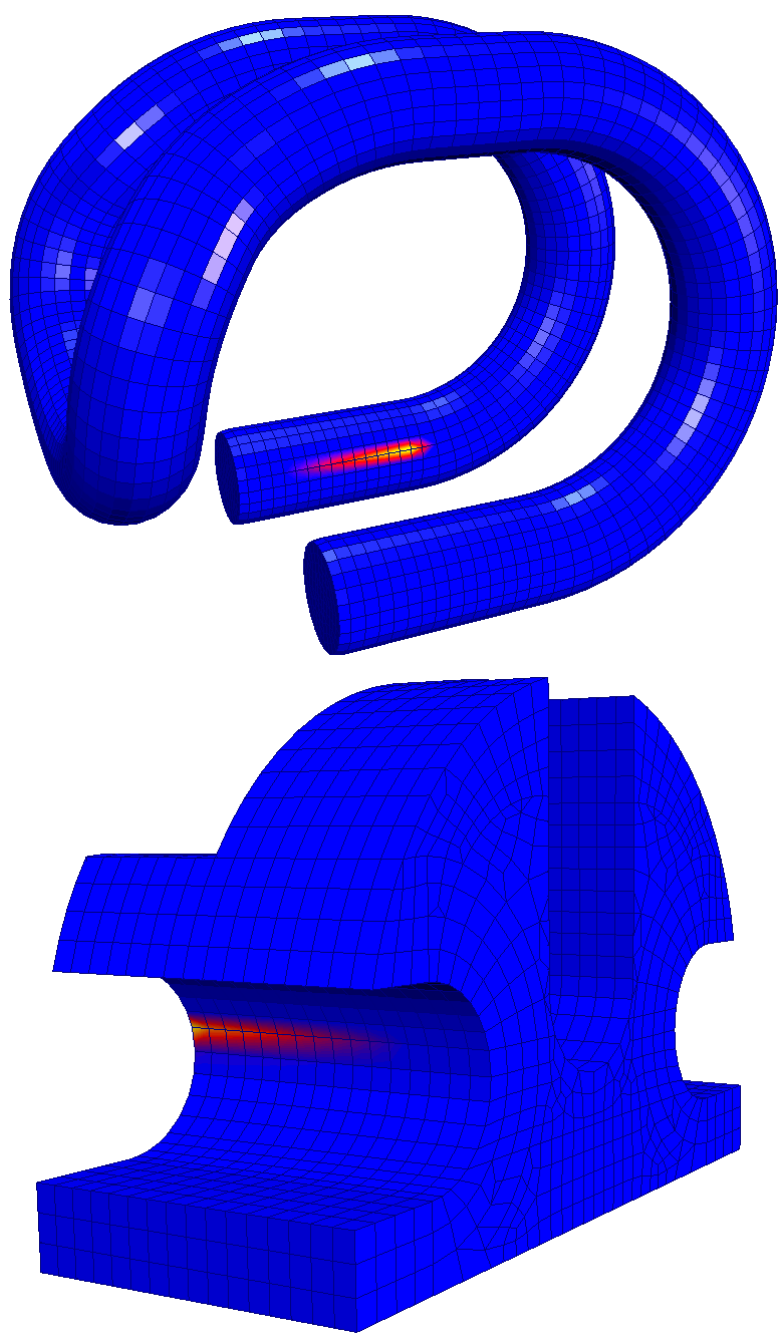

Fig. 10 Distribution of contact stresses on the surface of the spring clip (first) and the anchor head (second) for coordinated FE meshes

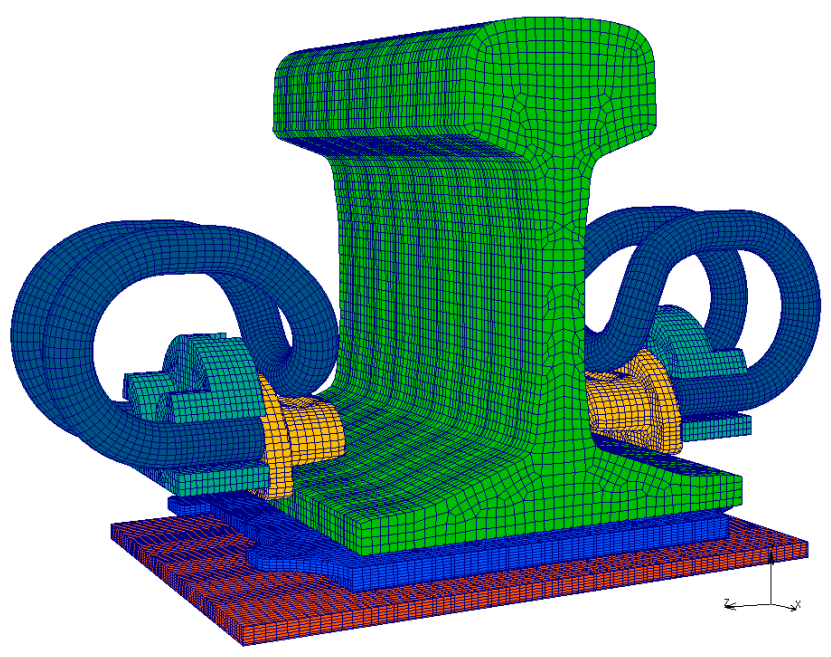

Fig. 11 FE model of the rail fastening assembly

\section{Verification of solutions}

For checking of the correctness of the solutions were measured deflection of elastic clips in the mounted rail fastenings. In particular, we studied the SB-3 rail fastenings with elastic clips SB7 for connection of the rails UIC60 to the sleepers. Measurements were carried out at the site relatively new track no. 133 Dąbrowa Górnicza Ząbkowice - Kraków Główny (10,70 km Dorota). Fig. 12 shows the measurement points of clip deflection relative to the anchor head.

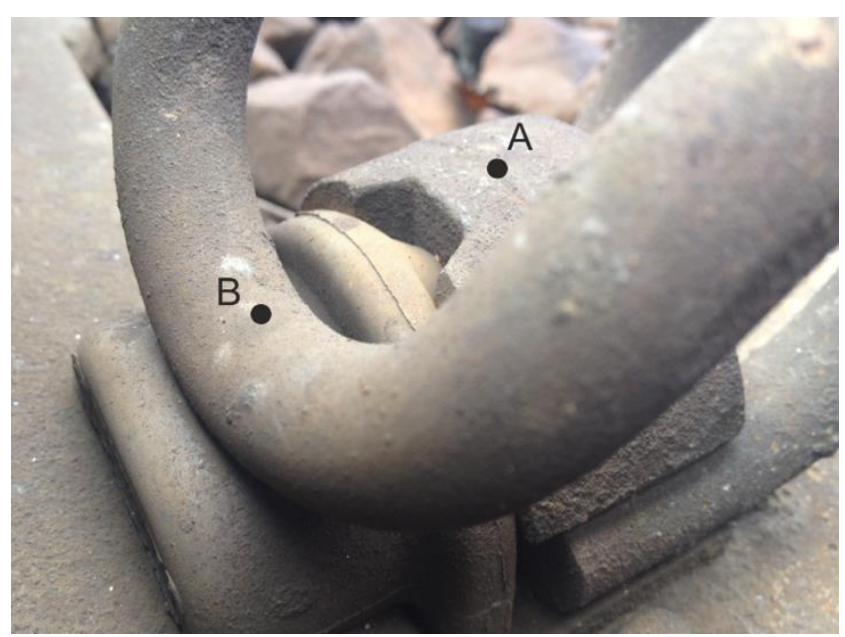

Fig. 12 The measurement points of clip deflection relative to the anchor head when measured in real conditions

The method of calculation adopted by the authors required define the level difference between the highest point of the anchor (point A on the Fig. 13) and a point on the spring clip located at a maximum height of the slot in the hold down part (point B on the Fig. 13).

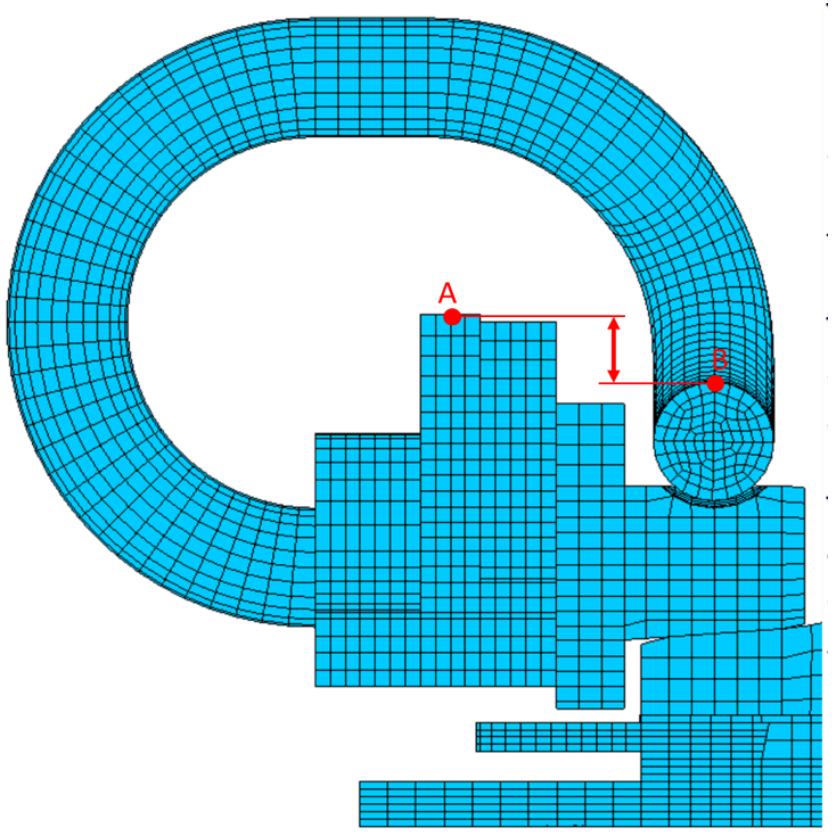

Fig. 13 The measurement points of clip deflection relative to the anchor head at calculation using FEM

The difference in levels of point A and point B in fact determined the degree of deflection of the spring clip 
after fitting it in the rail fastening to the sleeper. The authors took measurements the difference of characteristic points $\mathrm{A}$ and $\mathrm{B}$. The average value determined on the basis of measurements on randomly selected sleepers and fastenings was $2.7 \mathrm{~mm}$. These data agree well with the results of calculations performed using the finite element method.

\section{Some results of solution}

Due to the ongoing research to determine the material properties, in particular the material properties of the rail pad and insulating insert, calculation results (Fig. 14) obtained using the proposed model should be regarded as estimated, and the model as testing. Therefore, this article does not consider the issues related to the loading of the assembly of rail fastening. Text calculations have produced the following results (selected sample sizes):

- the maximum value of reduced stress in spring clamps was around $1200 \mathrm{MPa}$ (Fig. 14, a); the yield strength of the clamp material is $1600 \mathrm{MPa}$;

- the maximum value of the contact stresses on the upper surface of the rail foot (under the insulating insert) was approx. $28 \mathrm{MPa}$ (Fig. 14, b).

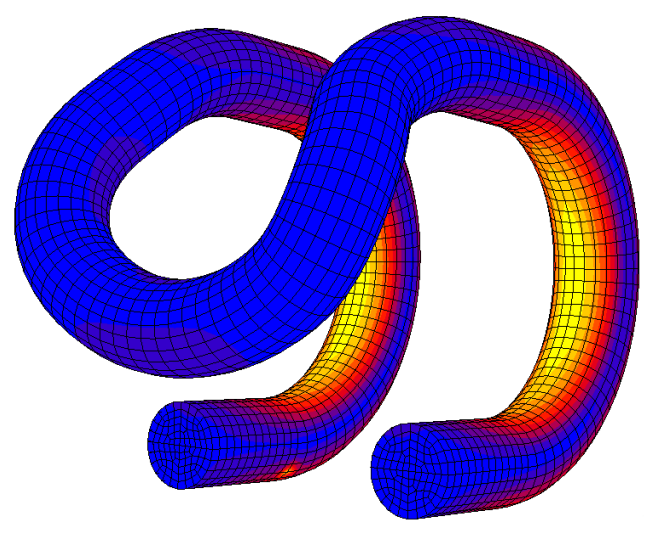

a

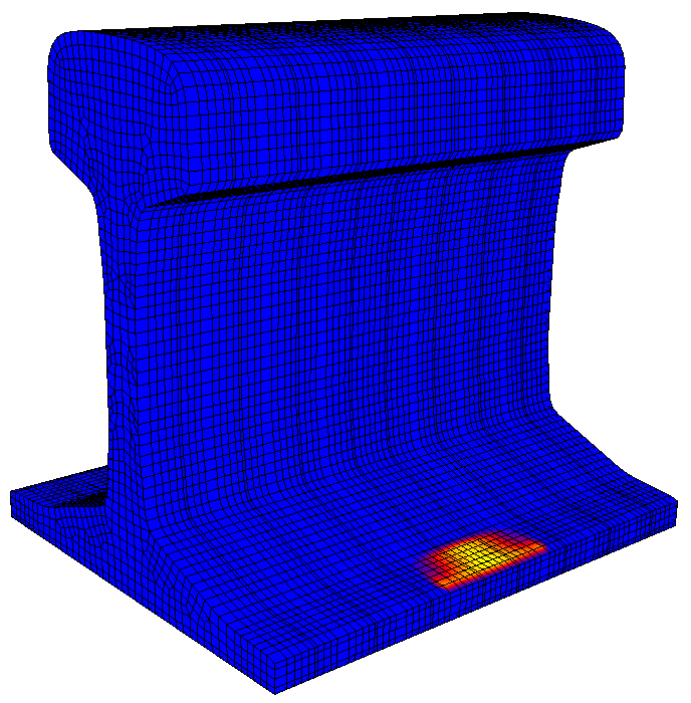

b

Fig. 14 Examples of the test calculation results: a - the distribution of reduced stress in spring clips; $b$ - the distribution of the contact stresses on the upper surface of the rail foot under the insulating insert

\section{Conclusions}

1. Based on the FEM was developed the technique, which allows the calculation of stress-strain state in the assemblies of rail fasteners. For inclusion in the discrete model the contact phenomenon should be expected with long calculations. In SB-3 rail fastening there are a lot of contact zones between different parts. It was necessary to take this into consideration at building of the discrete model to get a solution after a reasonable period of numerical calculations performed by PC.

2. Based on the proposed technique of semiautomatic coordination of contact nodes the test discrete model of SB-3 rail fastening was developed. The calculation results obtained using this model should be regarded as estimates and indicative. Fixed values of material properties will be replaced in the future on their variables nonlinear equivalents. Nonlinear material properties of certain parts of rail fastening are investigated by the authors and their implementation is being developed.

\section{References}

1. Bian, J.; Gu, Y.; Murray, M.H. 2013. A dynamic wheel-rail impact analysis of railway track under wheel flat by finite element analysis, Vehicle System Dynamics: International Journal of Vehicle Mechanics and Mobility 51(6): 784-797.

http://eprints.qut.edu.au/56693/1/A_dyanmic_wheelrail_impact_analysis_of_railway_track_under_wheel_fl at_by_finite_element_analysis_revision.pdf.

2. Harak, S.S.; Sharma, S.C.; Harsha, S.P. 2014. Structural dynamic analysis of freight railway wagon using finite element method, Procedia Materials Science 6: 1891-1898.

http://www.sciencedirect.com/science/article/pii/S2211 812814005860 .

3. Ju, S.H. 2007. Finite element analysis of structureborne vibration from high-speed train, Soil Dynamics and Earthquake Engineering 27(3): 259-273. http://dx.doi.org/10.1016/j.soildyn.2006.06.006.

4. Koszkul, J. 1995. Non-metallic materials. Laboratory exercises. Script. Częstochowa: Wydawnictwo Politechniki Częstochowskiej (in Polish).

5. Koszkul J. 1999. Polymer materials. Częstochowa: Wydawnictwo Politechniki Częstochowskiej (in Polish).

6. Martinod, R.M.; Betancur, G.R.; Restrepo, J.L.; Castañeda, L.F. 2016. Structural analysis of railways bolster-beam under commercial operation conditions: over-traction and over-braking, Transport Problems 11(2): 67-77.

http://transportproblems.polsl.pl/pl/Archiwum/2016/zes zyt2/2016t11z2_07.pdf.

7. Oczykowski, A. 2010. Research and development of elastic rail fasteting SB, Problemy Kolejnictwa 54(150): 121-156 (in Polish). http://www.problemykolejnictwa.pl/images/PDF/150_7 .pdf.

8. PN-EN $13146(1 \div 8)$ : 2003(U) "Railway applications Track - Test methods for fastening systems".

9. PN-EN $13481(1 \div 7)$ : 2004 "Railway applications Track - Performance requirements for fastening systems". 
10. Sladkowski, A. 2005. Accuracy analysis of the solution of spatial contact problem by means of the FEM, Mechanika 3(53): 17-21.

http://www.mechanika.ktu.lt/index.php/Mech/article/vi ew/13047/7047.

11. Sladkowski, A.; Sitarz, M. 2005. Analysis of wheelrail interaction using FE software, Wear 258(7-8): 1217-1223.

http://dx.doi.org/10.1016/j.wear.2004.03.032.

12. Tram track $1435 \mathrm{~mm}$. Warszawa ul. Kijowska [accessed 23.03.2012]. Available from Internet: http://www.garnek.pl/lumiks/20076979/tortramwajowy-1435mm-lok\#.

13. Wen, Z.; Jin, X.; Zhang, W. 2005. Contact-impact stress analysis of rail joint region using the dynamic finite element method, Wear 258(7-8): 1301-1309. http://dx.doi.org/10.1016/j.wear.2004.03.040.
A. Sładkowski, K. Bizoń

THE USE OF SEMI-AUTOMATIC TECHNIQUE OF FINITE ELEMENTS MESH GENERATION FOR SOLUTIONS OF SOME RAILWAY TRANSPORT PROBLEMS

S u m m a r y

Now for the build of tracks for main railway, subway or tram are using new designs of spring rail fastenings. These units are quite difficult to calculation, because they contain a number of contact connections. In the article developed the technique of numerical analysis of these fastenings, based on the use of the finite element method. The developed technique has been used for the analysis of SB-3 rail fastening.

Keywords: railway tracks; spring rail fastenings; finite element method; contact problems; semi-automatic mesh generation. 